Зайко Анна Геннадьевна

аспирант кафедры корпоративных финансов

и оценки бизнеса

Санкт-Петербургского государственного

экономического университета

\section{ПРИМЕНЕНИЕ КОЭФФИЦИЕНТА РАЗВИТИЯ ПРОЕКТА ПРИ ПРОГНОЗИРОВАНИИ ДЕНЕЖНЫХ ПОТОКОВ ПРЕДПРИЯТИЯ ЭНЕРГЕТИЧЕСКОГО МАШИНОСТРОЕНИЯ}

\begin{abstract}
Аннотация:
В статье рассмотрен и обоснован коэффициент развития проекта энергомашиностроительного предприятия. Разработана и описана формула, позволяющая вычислить модифицированную выручку по маситабным проектам с применением данного коэффициента. Проанализировано влияние, которое оказывает этот механизм на прогнозирование денежных потоков компании. Предложены рекомендации по использованию модифицированной выручки при принятии управленческих решений в энергомашиностроительной организации.
\end{abstract}

Ключевые слова:

энергетическое машиностроение, EPC-проект, коэффициент развития проекта, проект длинного цикла, прогнозирование денежных потоков.
Zaiko Anna Gennadievna

PhD student

Department of Corporate Finance and Business Valuation,

Saint-Petersburg State University of Economics

\section{APPLICATION OF THE PROJECT \\ DEVELOPMENT RATIO \\ IN FORECASTING \\ CASH FLOWS OF \\ THE POWER ENGINEERING ENTERPRISE}

Summary

The article considers and substantiates the project development ratio of the power engineering enterprise. The research developed and described the formula that allows one to calculate the modified revenue for largescale projects. The author analyzes the influence of the developed algorithm on the forecast of the company's cash flows. The article offers recommendations on the use of modified revenue while making management decisions in the power engineering enterprise.

Keywords:

power engineering, EPC project, project development ratio, long cycle projects, cash flow forecasting.

Нестабильная ситуация, сложившаяся в отечественной экономике в последние годы, приводит к ряду негативных последствий в российской промышленности, в том числе снижению доли авансирования проектов длинного цикла. Это является причиной недополучения денежных средств, которые были ранее отражены в финансовом плане крупных промышленных предприятий. Вопрос учета и прогнозирования денежных потоков по масштабным проектам приобретает все большую актуальность в ужесточившихся рыночных условиях.

В наших предыдущих работах показано, что ЕРС-проекты энергомашиностроительного предприятия [1] имеют длительный срок исполнения (3-5 лет), они характеризуются небольшим количеством, но при этом значительным объемом средств заказчика [2, с. 447]. Движение больших объемов денежных средств (аванса, платежей по поставке оборудования, пусконаладке и вводу в эксплуатацию) зачастую оказывается неравномерно распределено во времени. Например, в первый год исполнения контракта предприятие получает аванс, во второй и третий годы платежи не осуществляются, а в четвертый год переводятся оставшиеся суммы. Подобные нелинейные поступления финансовых средств отражаются на отчетности компании, способствуя резкому изменению выручки и, следовательно, прибыльности, а также возникновению кассовых разрывов. Таким образом, при принятии управленческих решений организация должна иметь представление об объективной картине в отношении текущих и будущих денежных потоков независимо от резких колебаний выручки.

На необходимость учета особенностей платежей по крупным контрактам в сорере промышленности и строительства при прогнозировании деятельности предприятий обращали внимание многие авторы [3]. В частности, рассматривалось значительное влияние поступлений денежных средств по долгосрочным контрактам на финнансовое состояние компании, отражаемое в бухгалтерской отчетности.

В данном исследовании анализируется деятельность крупнейшего в России энергомашиностроительного ПАО «Силовые машины» [4]. В соответствии с учетной политикой выручка и себестоимость крупных проектов признается компанией исходя из степени выполнения контрактов на отчетную дату, определенной как отношение понесенных затрат на работы по состоянию на эту дату к общим ожидаемым результатам по контракту [5]. При этом организация руководствуется 
пунктом 6 Положения по бухгалтерскому учету «Доходы организации» ПБУ 9/99, в котором указано, что «выручка принимается к бухгалтерскому учету в сумме, исчисленной в денежном выражении, равной величине поступления денежных средств» [6]. Согласно пункту 13 возможно признание выручки от реализации контрактов с длительным циклом по мере их выполнения.

Таким образом, в пределах бухгалтерского учета предприятие может влиять на принятие к учету выручки. В процессе прогнозирования в рамках управленческого учета возможно применение специальных инструментов, которые помогают в вычислении данных особенностей основной деятельности компании.

В 2016 г. ПАО «Силовые машины» обнародовало выручку от крупных контрактов (в том числе долгосрочных договоров на строительство) в размере 37894 млн р. (около 80 \% от общей прибыли за 2016 г.) [7]. Данный фракт свидетельствует о ключевой роли, которую играют крупные контракты в деятельности холдинга. Следовательно, учет долгосрочных договоров на строительство предполагает надежную оценку будущих затрат компании, необходимых для выполнения контрактных обязательств. Эти оценки прямо влияют на суммы и сроки признания выручки, так как определяют степень выполнения контракта.

В целях сбалансированного прогнозирования денежных потоков по крупным проектам мы разработали коэфффициент развития проекта. Его экономический смысл заключается в возможности равномерно распределить выручку и себестоимость по проекту по годам исполнения. Данный коэфффициент можно выразить следующей формулой:

$$
\left\{\begin{array}{l}
\mathrm{K}_{\mathrm{P} \Pi t}=\frac{\mathrm{P}_{\Pi t}}{\sum \mathrm{P}_{\Pi}} \\
\sum \mathrm{K}_{\mathrm{P} \Pi t}=1
\end{array},\right.
$$

где К Кпt - коэффрициент развития проекта за период $t$;

$\sum \mathrm{P}_{n}$ - совокупные ожидаемые затраты по проекту (объем выполненных работ по контракту);

$\mathrm{P}_{п t}$ - ожидаемые затраты по проекту за период $t$.

Коэффициент развития проекта является показателем, который позволяет равномерно распределить приток денежных средств в течение срока исполнения проекта в целях прогнозирования. Объем выполненных работ определяется при вычислении соотношения затрат, отнесенных к реализации контракта по состоянию на отчетную дату, и совокупных прогнозируемых расходов в рамках проекта.

Далее необходимо вычислить модифицированную выручку по проекту за отчетный период нарастающим итогом. Она определяется произведением планируемой совокупности платежей по контракту за все периоды его выполнения и коэффицциента развития проекта в конкретном году:

$$
\mathrm{B}_{\mathrm{M} t}=\left(\sum_{i=1}^{n}\left(\mathrm{~B}_{t}\right) \times \mathrm{K}_{\mathrm{P} \Pi t}\right)+\mathrm{B}_{\mathrm{M} t-1} \text {. }
$$

Графически механизм сглаживания модифицированной выручки с учетом фактических затрат и коэффициента развития проекта представлен на рисунке 1. В данном случае модифицированная выручка распределяется по трем платежам пропорционально степени выполнения проекта (2013 г. - аванс, 2016 г. - платеж по изготовлению и отгрузке оборудования, 2018 г. платеж по пусконаладке и вводу в эксплуатацию).

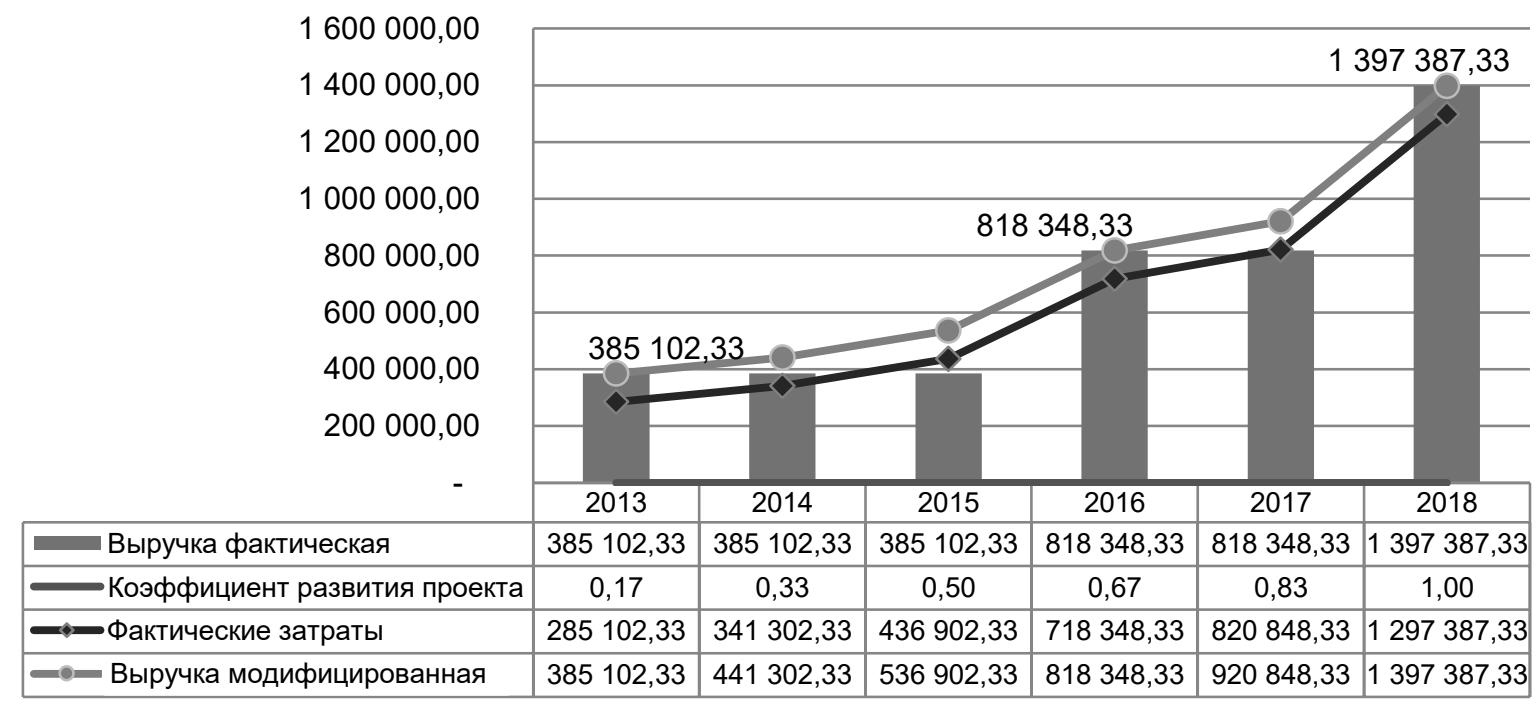

Рисунок 1 - Применение коэффициента развития проекта при вычислении модифицированной выручки, тыс. $\mathbf{p}$. 
Таким образом, мы получаем пропорциональное движение модифицированной выручки и фрактических затрат по контракту, при этом сглаживаются периоды, в которые не наблюдался приток денежных средств (2014, 2015 и 2017 гг.). В эти промежутки времени модифицированная выручка оказывается больше фрактической, поскольку работы продолжают выполняться, несмотря на приостановление начисления фактической выручки по платежам заказчика. Данный механизм удобен для крупных энергомашиностроительных предприятий, поскольку позволяет анализировать текущую ситуацию по каждому реализуемому ЕРС-проекту с опорой на аналитическое представление об уровне доходов и расходов холдинга по нему.

Сумму плановых расходов по договору необходимо ежемесячно обновлять с учетом прогнозируемых изменений, включая движение курсов валют для расходов в иностранной валюте, пересмотр условий контрактов с заказчиками и поставщиками и т. д. В связи с долгосрочностью исполняемых контрактов оценке присущи погрешности, которые могут оказать существенное влияние на текущие и будущие результаты деятельности энергомашиностроительного предприятия. Тем не менее модель может быть скорректирована исходя из изменений в плановых величинах и адаптирована для каждого отдельного проекта.

Таким образом, в целях прогнозирования денежных потоков энергомашиностроительного предприятия применение рассмотренного коэфффициента целесообразно, поскольку данный механизм позволяет стабилизировать денежные потоки компании как для признания выручки в бухгалтерском учете, так и при принятии управленческих решений. При этом основным направлением планирования фринансовых потоков энергомашиностроительной компании является выравнивание поступлений и платежей по крупным контрактам, что дает возможность создать гибкую систему контроля за ресурсами организации.

\section{Ссылки и примечания:}

1. ЕРС-проект (англ. - Engineering Procurement Construction) - это контракт, в рамках которого энергомашиностроительная компания выполняет весь цикл от разработки проекта, изготовления оборудования, строительства здания до шефр-монтажа и сдачи под ключ готовой к работе электростанции.

2. Зайко А.Г. Влияние плана контрактации энергомашиностроительного предприятия на формирование операционных денежных потоков // Экономика и предпринимательство. 2016. № 11-2 (76-2). С. 444-449.

3. Niven P.R. Balanced scorecard step by step: maximizing performance and maintaining results. N. Y., 2006. 336 p.

4. Офрициальный сайт ПАО «Силовые машины» [Электронный ресуpc]. URL: http://www.power-m.ru/company/ (дата обращения: 18.03.2017).

5. Годовой отчет ПАО «Силовые машины» по РСБУ за 2016 г. [Электронный pecypc]. URL: http://www.power-m.ru/upload/iblock/2f3/pm_fs_rap_2016m12.pdf (дата обращения: 15.03.2017).

6. Об утверждении Положения по бухгалтерскому учету «Доходы организации» ПБУ 9/99 [Электронный ресурс] : приказ Минфина РФ от 6 мая 1999 г. № 32н. Доступ из справ.-правовой системы «КонсультантПлюс».

7. Годовой отчет ...

\section{References:}

Niven, PR 2006, Balanced scorecard step by step: maximizing performance and maintaining results, New York, 336 p., https://doi.org/10.1002/9781119205081.

Zaiko, AG 2016, 'Influence of power engineering enterprise's contract plan on the formation of operating cash flow', Ekonomika i predprinimatel'stvo, no. 11-2 (76-2), pp. 444-449, (in Russian). 